\section{SPOMINI NA USTANOVITEV DRUŠTVA ZA ANTIČNE IN HUMANISTIČNE ŠTUDIJE SLOVENIJE}

Predlog predsednice Barbare ŠegaČeh, da 20-letnico društva proslavimo $\mathrm{s}$ spomini dosedanjih predsednikov na delovanje društva, se mi zdi zelo posrečen in primeren. Resda so dokumenti o ustanovitvi in začetnem delovanju društva shranjeni v arhivu; toda arhivski dokumenti so pogosto zelo suhoparni in birokratsko togi; veliko bolj živo je ustno izročilo, ki ga ohranjajo udeleženci takratnega dogajanja. Zato je spomine na dogajanje treba reševati, dokler udeleženci še živijo. Pozneje zna biti prepozno. Naj navedem konkreten primer: med obema svetovnima vojnama je v Sloveniji delovalo Društvo prijateljev humanistične gimnazije, ki je naslovilo na slovensko javnost več spomenic. Podatkov o tem društvu nisem mogel izbrskati nikjer. Menda je bil duša tega društva Josip Debevec, znani prevajalec Dantejeve Božanske komedije, eden najbolj aktivnih sodelavcev pa tudi Anton Sovre.

Nas seveda zanima vprašanje, kdaj in kje je prvič vzniknila ideja za ustanovitev slovenskega društva klasičnih filologov ali poznavalcev in ljubiteljev antike.

V petdesetih letih je obstajal aktiv profesorjev latinščine, ki se je sestajal v prostorih nekdanje klasične gimnazije (današnje Osnovne šole Prežihovega Voranca). Toda to še ni bilo društvo, čeprav je naredilo tudi že nekaj korakov v tej smeri.

Nekoč sem še kot asistent svojemu predstojniku prof. Grošlju postavil vprašanje, ali ne bi bilo primerno ustanoviti društva, ki bi se bojevalo za obstoj latinščine in grščine in klasič- ne gimnazije. Njegovega odgovora se dobro spominjam: »Bolje je, dragi kolega, da se v javnosti o nas čim manj govori. Obstoj naše stroke visi na nitki. Če bomo ustanovili društvo, bo to nekakšen razredni sovražnik, ki bo vsem na očeh. Zato je bolje, da smo čim manj opazni. «Ob tem mi je omenil, da je pred kratkim prišlo do obiska tričlanske delegacije slovenskih klasičnih filologov (prof. M. Grošelj - ravnatelj Danilo Golob - prof. Lilijana Avčin) pri dr. Joži Vilfanu, takratnem podpredsedniku slovenske vlade. Čeprav je bil dr. Joža Vilfan zelo razgledan izobraženec in tudi osebno naklonjen latinščini (sam mi je pozneje nekoč, po enem Štihovih večerov v hotelu Slon, pripovedoval, da ima doma celo serijo dvojezičnih, latinsko-francoskih izdaj antičnih klasikov), vendar omenjeni delegaciji ni dal nikakršnega upanja, da bi bilo mogoče v tem pogledu kaj premakniti na bolje. Na koncu pogovora me je prof. Grošelj vprašal: "In če smo dobili takšen odgovor od dr. Joža Vilfana, kaj mislite, da se bo za latinščino bojeval Miha Marinko?«

Leta 1974 so jugoslovanski klasični filologi prevzeli obvezo, da organizirajo kongres Eirene v Dubrovniku. Eirene je bila zveza društev klasičnih filologov takratnih socialističnih držav. Jugoslavija (kot neuvrščena) sicer ni bila polnopravna članica Eirene, temveč samo opazovalka; kljub temu je prevzela obvezo, da organizira kongres Eirene, za kraj kongresa pa je bil izbran Dubrovnik. Dubrovniški kongres, ki je bil po soglasni sodbi udeležencev eden najbolje organiziranih kongresov Eirene, je pomenil izredno afirmacijo naše stroke. Prof. Grošelj je mene predlagal v pripravljalni odbor tega kongresa, ki se je več kot eno leto sestajal $\mathrm{v}$ prostorih takratne Ju- 
goslovanske akademije znanosti in umetnosti (JAZU) v Zagrebu. Pripravljalni odbor je uglednega zagrebškega latinista, podpredsednika JAZU, prof. Veljka Gortana izvolil za predsednika, mene pa za tajnika kongresa. Na sestankih pripravljalnega odbora je bilo sprejeto priporočilo, naj se ustanovijo republiška društva za antične študije (Hrvatje so takšno društvo že imeli), nato pa naj se republiška društva povežejo v Zvezo društev za antične študije Jugoslavije. Čeprav sem se branil, sem prevzel moralno obveznost, da pripravim ustanovitev ustreznega društva v Sloveniji.

Tako po koncu dubrovniškega kongresa sem se lotil dela. Po predpisih je društvo lahko ustanovila skupina najmanj desetih ustanovnih članov, programsko zasnovo društva je morala odobriti Republiška konferenca SZDL, nato pa se je društvo registriralo pri Državnem sekretariatu za notranje zadeve.

Ni bilo težko najti deset podpisnikov. Brez težav smo se dogovorili tudi za ime društva: ne društvo klasičnih filologov, kot ga imajo npr. Hrvati, ampak Društvo za antične in humanistične študije, čeprav je bilo pri tem precej diskusije in pomislekov ob oznaki 'humanističen'. Nato so sledila mukotrpna pogajanja na SZDL, kjer bi rajši videli, da se oblikujemo kot sekcija v okviru kakega že obstoječega društva (npr. Društva za tuje jezike ali Zgodovinskega društva). Vendar nismo odnehali in ne popustili. Nazadnje smo po poldrugem letu pogajanj vendarle dosegli vpis v register društev.

Sledil je boj za denarna sredstva pri takratnih samoupravnih interesnih skupnostih (Kultura skupnost, Izobraževalna skupnost), ki je trajal kaki dve leti. Končno smo si izvojevali nekaj skromnih, simboličnih sredstev, toda to je bila kljub pičlemu znesku dobra štartna osnova: kdor se je enkrat znašel na spisku PISa, ga zlepa niso več brisali s spiska, s spretnimi manevri so se mu lahko sredstva iz leta $v$ leto tudi povečala; in te spiske so nato po osamosvojitvi Slovenije - podedovala tudi sedanja ministrstva.

Prvi društveni odbor smo sestavljali: podpisani kot predsednik, Silvo Kopriva (podpredsednik), Matija Pogorelec (tajnik), Zdenka Beran (blagajničarka), Primož Simoniti, Katja Pavlič (predstavnica študentov); Erika Mihevc-Gabrovec je bila predsednica nadzornega odbora.

Komaj kak mesec po ustanovitvi je društvo doživelo svoj ognjeni krst: Matija Pogorelec, tajnik društva, je po svojih zvezah dobil v roke zaupni dopis, ki ga je Ana Tomić v imenu mestnega Zavoda za šolstvo poslala vsem ljubljanskim osnovnim šolam, naj ne ustanavljajo novih latinski paralelnih razredov, že obstoječe latinske paralelke pa naj ukinejo. Dopis je bil v prvi vrsti namenjen Osnovni šoli Prežihovega Voranca, kjer je že leta divjala načrtna histerična gonja proti latinskim paralelkam, ki so tam obstajale kot zadnji ostanek nekdanje državne klasične gimnazije. Čeprav je bil dopis navidez usmerjen le proti pojavu elitizma, je bil v resnici naperjen proti pouku latinščine nasploh.

Dilema, pred katero se je znašel takratni društveni odbor: naj na ta zaupni dopis reagiramo ali ne? Najmanj, kar smo lahko pričakovali, je bila ukinitev društva, če bomo drezali v tako delikatno temo, kot jo je takrat v uradni ideologiji predstavljala t. i. zunanja diferenciacija in pojav elitizma. Matija Pogorelec, ki se je kot nepooblaščena oseba dokopal do tega dopisa, je seveda tvegal največ. Kljub temu je predlagal, da zavzamemo moško in 
trdno stališče. Sestavil sem posebno protestno izjavo, s katero se je odbor v celoti strinjal. Kot predsednik društva sem prevzel obveznost, da to izjavo objavim v sredstvih javnega obveščanja.

Naslednje jutro sem odšel v uredništvo Dela, k Titu Vidmarju, uredniku kulturne rubrike. Predlaganega besedila ni hotel objaviti kot izjave društva, češ da to ni v skladu z uredniško politiko: takšno izjavo bi lahko objavili le s soglasjem RK SZDL. Vedel sem, da bi to pomenilo najmanj polletno zavlačevanje in "mehčanje«, saj SZDL na naše ostro besedilo ne bi dala svojega blagoslova. Pač pa mi je predlagal, da lahko besedilo objavim v svojem osebnem imenu, kot individualni podpisnik, seveda $z$ vsem osebnim tveganjem. Po telefonskem posvetu s člani odbora sem besedilo podpisal $\mathrm{v}$ svojem imenu in ga objavil kot svoj osebni izdelek (kar je v resnici tudi bil). V takšni obliki je bilo besedilo takoj naslednji dan brez cenzure v Delu objavljeno pod naslovom Zavř̌ena klasika. Odmev je bil silovit. Na Osnovni šoli Prežihovega Voranca je bil sklican masovni roditeljski sestanek, ki se je razbesnel v pravi vihar. DELO je dobilo toliko pisem bralcev na to temo, da jih čez nekaj dni ni več hotelo objavljati, pač pa je namesto tega objavilo neko izjavo OO ZKS Zavoda za šolstvo pod demagoškim naslovom Nihče ne preganja latinščine iz osnovne šole, kjer je bilo med drugim svetohlinsko zapisano, da si bodo celó "prizadevali za razširitev pouka latinščine in tudi za pouk drugih klasičnih jezikov, npr. grščine«. Seveda iz teh bombastičnih obljub ni bilo nič. Pri nekih mojih znancih sem še čez pol leta, ko sem prišel na obisk, videl izrezek iz Dela $z$ naslovom $»$ Zavržena klasika« prilepljen na sobno omaro.
Odmeve na to polemiko so objavljali tudi drugi časopisi - Ljubljanski dnevnik, Pavliha, Sodobnost, Naši razgledi. Latinščina je sicer izgubila bitko, ni pa izgubila vojne. Že obstoječi homogeni latinski razredi na Osnovni šoli Prežihovega Voranca so bili sicer v resnici ukinjeni. Vendar je ravno ta akcija naredila latinščino $\mathrm{v}$ takratnih »svinčenih letih« tudi politično atraktivno in zanimivo kot eno redkih oblik intelektualne opozicije proti tedanji uradni ideologiji. Zanimanje za pouk latinščine je vidno poraslo in tudi najbolj zadrti nasprotniki na zavodu za šolstvo so nas poslej otipavali s precejšnjim rešpektom, čeprav svojega odklonilnega odnosa do latinščine in klasike oziroma do naše stroke in do naših pogledov na vzgojo in izobraževanje niso mogli prikriti.

Društvu sem predsedoval štiri leta. Delo sem opravljal z veseljem, bilo je zanimivo in prijetno, saj sem imel okrog sebe zanesljive, požrtvovalne in pogumne sodelavce. Organizirali smo številna posvetovanja in predavanja, tekmovanja iz latinščine za srednješolce, zbirali smo sredstva za sofinanciranje Žive antike itd.

Po štirih letih sem vodstvo društva izročil prof. dr. Primožu Simonitiju, ki mi je že dotlej stal ob strani kot moja desna roka. Sam pa sem prevzel novo funkcijo: po takratnem ključu je na Slovenijo prešla vrsta, da prevzame Zvezo društev za antične študije Jugoslavije. Postal sem predsednik Zveze in moja sodelavka, prof. dr. Erika Mihevc-Gabrovec, je postala tajnica Zveze. Poleg drugih obveznosti (zagotovitev sredstev za članstvo v FIEC oz. sploh včlanjenje $v$ to najvišjo mednarodno znanstveno organizacijo za našo stroko, sodelovanje v raznih mednarodnih akcijah itd.) je bila moja poglavitna naloga, da organiziram obšir- 
no znanstveno zborovanje na zveznem nivoju. Organizirali smo znanstveno zborovanje v Žalcu, ki je bilo strokovno na zavidljivi višini, zagrenile pa so ga razne balkanske in bizantinske spletke, podobne tistim, zaradi katerih se je sedem let pozneje sesula Jugoslavija.

Toda o tem ob kaki drugi priložnosti.

Kajetan Gantar

\section{POUČEVANJE LATINŠČINE V VZHODNI EVROPI: \\ AKTUALNO STANJE IN MOŽNOSTI RAZVOJA}

Poročilo o mednarodnem simpoziju (Trst, 7. - 9. 7. 2000)

Trst je že zaradi svoje geografske lege stična točka med vzhodno in zahodno Evropo: ni čudno torej, da je francoska organizacija Union Latine izbrala prav to mesto kot sedež za simpozij o poučevanju latinščine v vzhodni Evropi. Vabilu se je odzvalo precejšnje število univerzitetnih profesorjev in srednješolskih učiteljev klasičnih jezikov, srečanja pa so se udeležili tudi drugi, ki se za poučevanje latinščine zanimajo posredno, na primer cerkveni predstavniki in založniki. Večina udeležencev je prišla iz vzhodne Evrope (Poljske, Makedonije, Črne gore, Romunije, Bolgarije, Ukrajine, Madžarske, Estonije, Češke, Albanije, Latvije, Rusije, Slovaške, Litve, Hrvaške, Slovenije), sodelovali pa so tudi predavatelji iz Francije, Śpanije, Nizozemske in Italije.

Preden nakažemo potek in dosežke simpozija, je vsekakor primerno, da nekaj besed posvetimo organizaciji, ki je srečanje omogočila. Union latine je nastala leta 1954 in ima trenutno 35 članic - držav, v katerih govorijo pretežno romanske jezike. Zavzema se za širitev humanističnih idej in vrednot, ki izhajajo iz klasične grško-rimske tradicije, po vseh državah sveta, zlasti pa med tistimi narodi, ki jih povezuje skupna jezikovna identiteta (romanski jeziki) ali pripadnost evropski kulturi, ki jo je izoblikovalo latinstvo. $\mathrm{V}$ ta namen podpira društva, ki se ukvarjajo s študijem antike in humanističnih ved, širi didaktični material, organizira srečanja, financira tečaje.

K uspehu simpozija je nedvomno pripomogla pestrost tem, ki so jih predavatelji predstavili občinstvu. Beseda je tekla o ciljih in načrtih Unione latine (veleposlanik Gabriele Sardo in Dino De Poli), pomenu latinščine za Cerkev (msgr. Anacleto Pavanetto), razvoju klasične filologije v Franciji in prisotnosti motivov iz antičnega sveta v vsakdanjem življenju (filmih, romanih, oglasih) (prof. Claude Aziza), tečajih latinščine po televiziji (prof. Anton J. L. van Hoof), uporabnosti interneta pri pouku klasičnih jezikov (prof. José Joaquín Caerols), izzivih, ki jih latinščina danes postavlja založnikom (prof. Lamberto Pigini), ustanovitvi gimnazije Accademia della Magna Grecia, kjer naj bi se dijaki izražali zlasti v latinščini (Luigi Miraglia). Organizatorji (Ernesto Bertolaja, Francine Girond, Massimiliano Misturelli) so poskrbeli še za razbremenilni ogled arheološkega izkopavanja $v$ tržaškem mestnem jedru in slavnostno večerjo.

Predavanja in okrogle mize so bile vsekakor razporejene tako, da je udeležencem ostajalo še dovolj časa za vzpostavljanje medsebojnih stikov in snovanje načrtov za bodoče sodelovanje. 